\title{
Impact of COVID-19 pandemic on Primary Care Physicians' Work-Life Balance: Empirical Evidence from Primary Healthcare Corporation (PHCC) Qatar
}

Dr. Muhammad Atif Waheed ${ }^{1 *}$, Dr. Lolwa Al Mannai ${ }^{2}$, Dr. Moqthair Shareef ${ }^{1}$, Dr. Sadaf Akbar ${ }^{3}$, Dr. Sana Arooj $^{5}$, Dr. Ahmed Rashid Shaik ${ }^{1}$, Dr. Atif Zafar ${ }^{1}$, Dr Arshad Mehmood ${ }^{1}$, Dr. Muhammad Shahid Siddique ${ }^{1}$, Dr. Maxwell Slieman ${ }^{3}$, Dr. Wajahat Ali Mohammad ${ }^{1}$, Dr. Mohammed Ahmad Saad ${ }^{4}$, Dr. Shawqiya Salman Al Majid ${ }^{6}$, Dr. Samya Ahmad Al Abdulla $^{7}$

\footnotetext{
${ }^{1}$ Consultant family medicine, PHCC, Qatar

${ }^{2}$ Manager referral management office \& call centre, PHCC, Qatar

${ }^{3}$ Specialist family medicine, PHCC, Qatar

${ }^{4}$ General Practitioner/Physician in charge of the health centre, PHCC, Qatar

${ }^{5}$ Junior Doctor

${ }^{6}$ Manager of the health centre, PHCC, Qatar

${ }^{7}$ Executive Director of Operations, PHCC, Qatar
}

DOI: $10.36347 /$ sjams.2022.v010i01.003

| Received: 25.11.2021 | Accepted: 30.12.2021 | Published: 07.01.2022

*Corresponding author: Dr. Muhammad Atif Waheed

Consultant family medicine, PHCC, Qatar

\section{Abstract}

\section{Original Research Article}

The COVID-19 pandemic has caused a significant set of challenges for healthcare providers. Therefore, it is of utmost importance to determine the anxiety, depression, stress, and burnout levels of employees and to identify subfactors that directly impact physicians' well-being. This is a cross-sectional online survey evaluating the impact of the COVID-19 pandemic on work-life balance, in particular, psychological distress on practising primary care physicians at Primary Healthcare Corporation, Qatar. We designed an online survey using the stress component of DASS-21, GAD-7, PHQ9, and the Stanford Professional Fulfilment Index (PFI). A total of 150 (21\%), of which 58.7\% were males and 47\% were 25-44 years old, completed the questionnaire. Stress was reported by $(26.7 \%)$, anxiety $(32.7 \%)$, depression $(45.3 \%)$, burnout $(38.7 \%)$ and low professional fulfilment $(80 \%)$. Stress and burnout were more prevalent among physicians aged < 44 years. Physicians who were concerned about the impact of COVID-19 on themselves reported higher levels of stress, anxiety, and depression $(p<.05)$. Physicians who expressed burnout were more likely to order the wrong medication $(p=.046)$ and those with stress, anxiety, and depression were more likely to cause major medical errors that could have resulted in patient harm $(\mathrm{p}<.05)$. The level of satisfaction with salary was associated with stress $(p=.047)$ and depression $(p=.005)$. Telephone consultation dissatisfaction was significantly associated with stress $(p=.006)$, anxiety $(p=.028)$, depression $(p=.010)$ and burnout $(p=.038)$. Gender, marital status, number of dependents, choice of the medical profession willingly or unwillingly, availability of PPE, and the rapidly changing COVID-19 guidelines were not associated with the variables. Stress, anxiety, depression, burnout, and low professional fulfilment were common among PHCC physicians. The PHCC has an excellent support system for primary care physicians. However, further effective communication strategies that are empathetic, not fear-based, and physician-centred, along with retraining of virtual consultation and provision of online interpreter services, are advised.

Keywords: COVID-19, Physicians, Survey, Work-life balance, psychological distress.

Copyright $\odot 2022$ The Author(s): This is an open-access article distributed under the terms of the Creative Commons Attribution 4.0 International License (CC BY-NC 4.0) which permits unrestricted use, distribution, and reproduction in any medium for non-commercial use provided the original author and source are credited.

\section{INTRODUCTION}

The COVID-19 pandemic has jeopardised human lives worldwide. At the time of writing this article, April 21, 2021, 16:03 GMT +3 hours, confirmed cases of COVID-19 were 142,238,073, and mortality was 3,032,124 ("WHO Coronavirus (COVID-19) Dashboard", 2021). Healthcare workers during the 
Muhammad Atif Waheed et al; Sch J App Med Sci, Jan, 2022; 10(1): 15-24

current COVID-19 pandemic and in previous pandemics, such as the 2003 SARS outbreak, have shown high levels of stress, anxiety, depression, and fear of infection. Psychological distress impacts physicians' emotional well-being and disturbs work-life balance with many negative consequences, such as job performance. The work-life balance (WLB) is an equilibrium state in which people's jobs and lives are equal (Lockwood, 2003). It is a liaison between home and work that allows one to have personal advancement while staying within the confines of current interests (Lindfelt et al., 2018). The WLB concept is perceived differently by different stakeholders, and there is no universally accepted definition for this concept (Hirchi et al., 2019). For example, WLB is viewed as a problem for employees in terms of balancing employment and family obligations; from the perspective of managers and employers, it is a struggle to maintain a positive work environment to support employees in focusing on their jobs (Lockwood, 2003). Disequilibrium in worklife balance can lead to physician burnout. Burnout is a psychological syndrome that occurs due to constant exposure to stressful work conditions, leading to adverse emotional reactions (Dinibutun, 2020). Furthermore, burnout is categorised into three types: depersonalisation, emotional exhaustion, and personal accomplishment, which are independent of each other. Physician burnout has severe consequences at the individual level, healthcare system level, and patient care level. It leads to poor self-care, road traffic accidents, substance misuse, depression, and a double risk of suicidal ideation at the individual physician level compared to the general population.

Healthcare workers are at a higher level of burnout due to extensive stress in their jobs due to the COVID-19 pandemic. The factors that are significant contributors to poor mental health outcomes among physicians are extended working hours, shift patterns, and complexity in relationships with colleagues, patients, and their families (Dinibutun, 2020). Furthermore, lack of specific drug treatment, extensive media coverage, and a sense of insufficient support (Lai et al., 2020), increased exposure to COVID-19, increased workload, ethical quandaries involved in care, continuous change in scope of practise (for example, telemedicine instead of traditional face-to-face consultations, and evolving COVID-19 guidelines), exposure to disease, quarantine, and concerns about one's own health (Kannampallil et al., 2020). Psychological distress and burnout reduce physicians' efficiency and productivity at the healthcare system level, increase physicians' turnover, reduce patient access to care, and raise the cost of care; from the patient's perspective, burnout in physicians' results in more medical mistakes, more extended recovery periods, more inadequate provision of quality of care, and meagre patient satisfaction (West et al., 2018). A study from China found a high prevalence of anxiety, depression, insomnia, and distress in healthcare workers who treated COVID-19 patients (Lai et al., 2020). Thus, there have been concerns regarding healthcare professionals' mental health who are already overworked and exhausted from the COVID-19 pandemic (Casigliani, 2020). In another study, physicians were found to have higher levels of anxiety and hopelessness than the general population, and nurses had a higher level of anxiety and hopelessness than physicians (Hacimusalar et al., 2020).

The objectives of this research were to thoroughly examine the impact of the COVID-19 pandemic on primary care physicians' work-life balance at the Primary Health Care Corporation, Qatar.

\section{Research Question}

What is the extent of the impact of the COVID-19 pandemic on the work-life balance (WLB) of primary care physicians at the primary healthcare corporation, Qatar?.

\section{Materials ANd MethodS}

The empirical analysis followed a positivistic paradigm with quantitative methodology to determine psychological distress (stress, anxiety, depression), burnout, professional fulfilment, and subfactors through a well-designed research instrument. The research design was a cross-sectional survey design. Participants in this study were registered primary care physicians working within the primary healthcare corporation, Qatar. The questionnaire was sent using PHCC intranet email to 724 practising physicians from February $14^{\text {th }}$ to March $29^{\text {th }}$, 2021. A reminder email was sent to all physicians after the $4^{\text {th }}$ and $5^{\text {th }}$ weeks. The survey was meant to close four weeks after the start date, but it was extended due to unusual circumstances. Implied consent was included on the first page of the online questionnaire.

The major domains included in the questionnaire were demographics, general questions, PHQ-9, GAD-7, and the Stanford Professional Fulfilment Index. These were adapted from well-known reliable and validated questionnaires: the Patient Health Questionnaire PHQ-9 (Zhang et al., 2013), the General Anxiety Disorder GAD-7 (He et al., 2010), the Depression, Anxiety, and Stress Scale (DASS 21) using scale items 1, 6, 8, 11, 12, 14, and 18 (Sinclair et al., 2012) and the Stanford Professional Fulfilment Index (Trockel et al., 2018).

A total of 170 participated in the survey, out of a total of 724 physicians. The response rate of the study was $23.4 \%$. However, because approximately 20 primary care physicians did not complete the survey completely, their data were excluded from the study.

First of all, the reliability of the overall questionnaire was tested using Cronbach's alpha, which tests the internal consistency of a scale, and it revealed 
Muhammad Atif Waheed et al; Sch J App Med Sci, Jan, 2022; 10(1): 15-24

a value of 0.886 . A test value of between 0.7 and 0.95 is considered acceptable (Tavakol and Dennick, 2011).

Statistical analyses were performed using IBM SPSS (Statistical Package for Social Sciences, version 27) after transferring data from the Survey Monkey. The Shapiro-Wilcox test indicated the use of nonparametric tests as variables were not normally distributed. Items of the PHQ-9, GAD-7, and DASS-21 were scored to determine anxiety, depression, and stress among primary care physicians. Similarly, the Stanford Professional Fulfilment Index items, consisting of six items for professional fulfilment and ten items for overall burnout, were scored. Average scores of $\geq 3$ were used to determine professional fulfilment and average scores of $\geq 1.33$ for burnout, respectively (Trockel et al., 2018; O’Brien et al., 2021).

The chi-square test was used to determine the association of stress, anxiety, depression, burnout, and low professional fulfilment index among primary care physicians with socio-demographic factors, general questions factors, and medical errors using a critical or
$P$-value of .05. A Spearman's rank-order correlation test was used to determine the relationship between burnout, professional fulfilment, stress, anxiety, and depression, as it shows how two variables correlate, ranging from +1 to -1 , with 0 representing no correlation, +1 representing a perfect positive correlation, and -1 representing a perfect negative correlation, respectively.

\section{Data analysis and Results \\ Socio-demographics}

Age categories were regrouped into mainly three categories to facilitate statistical analysis. Around 47 percent were between the ages of 25 and 44, 38 percent were between the ages of 45 and 54, and 14 percent were over the age of 55. The majority of the respondents were men $(58.7 \%)$ compared to women $(41.3 \%)$, and $(94 \%)$ stated that they were married. About (30\%) were parenting two children, and (26.7\%) three children less than 18 years old. However, $14 \%$ of the respondents did not have any children. The sociodemographic characteristics of the participants are summarised in Table 1.

Table 1 : The sociodemographic characteristics of the participants $(N=150)$

\begin{tabular}{|c|c|c|c|}
\hline 2 & & Frequency & Percentage $(\%)$ \\
\hline & $25-44$ & 71 & 47 \\
\hline & $45-54$ & 57 & 38 \\
\hline & $>55$ & 22 & 14 \\
\hline & Total & 150 & 100 \\
\hline \multicolumn{4}{|l|}{ Gender } \\
\hline & Female & 62 & 41.3 \\
\hline & Male & 88 & 58.7 \\
\hline \multicolumn{4}{|l|}{ Relationship status } \\
\hline & Married & 141 & 94 \\
\hline & Widowed & 1 & 0.7 \\
\hline & Divorced & 1 & 0.7 \\
\hline & Separated & 2 & 1.3 \\
\hline & Single, never married & 5 & 3.3 \\
\hline \multicolumn{4}{|l|}{ No of children below 18 years } \\
\hline & None & 21 & 14 \\
\hline & 1 & 17 & 11.3 \\
\hline & 2 & 45 & 30 \\
\hline & 3 & 40 & 26.7 \\
\hline & 4 & 13 & 8.7 \\
\hline & More than 4 & 14 & 9.3 \\
\hline
\end{tabular}

\section{General Questions}

We asked about the satisfaction of participants with their salaries and with virtual consultations. The majority of respondents $(41.3 \%)$ were satisfied with virtual consultations, $(24 \%)$ were very satisfied, and
(23.3\%) were neutral. The majority of primary care physicians $(39.3 \%)$ were satisfied with their salaries. However, $(21.3 \%)$ were dissatisfied, and $(30.7 \%)$ were neutral. These are summarised in Figure 1. 


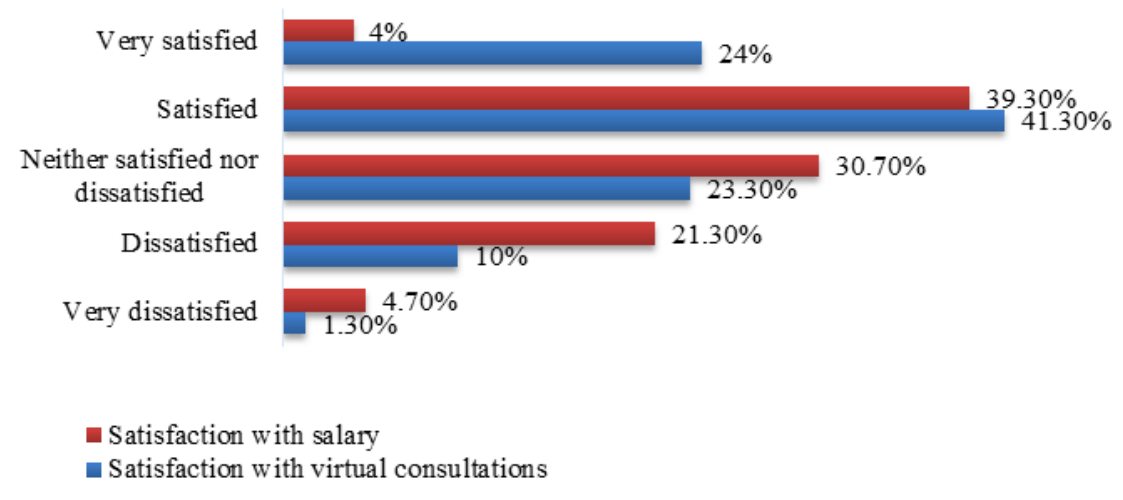

\section{Figure 1: Satisfaction with virtual consultations and salary}

When participants were asked about how worried they were if they got the COVID-19 infection personally, $45.3 \%$ replied that they were somewhat worried, $27.3 \%$ were very worried, and $15.3 \%$ were extremely worried. Similarly, when asked about how worried they are about their families if they get a COVID-19 infection, $28.7 \%$ of participants responded that they were somewhat worried, $36.7 \%$ were very worried, and $30.7 \%$ were extremely worried. How concerned would they be if they were placed in quarantine because they tested positive for COVID-19? The physicians responded that they would be very worried $(32.7 \%)$, extremely worried $(32.0 \%)$, and somewhat worried (19.3\%), as summarised in Figure 2.

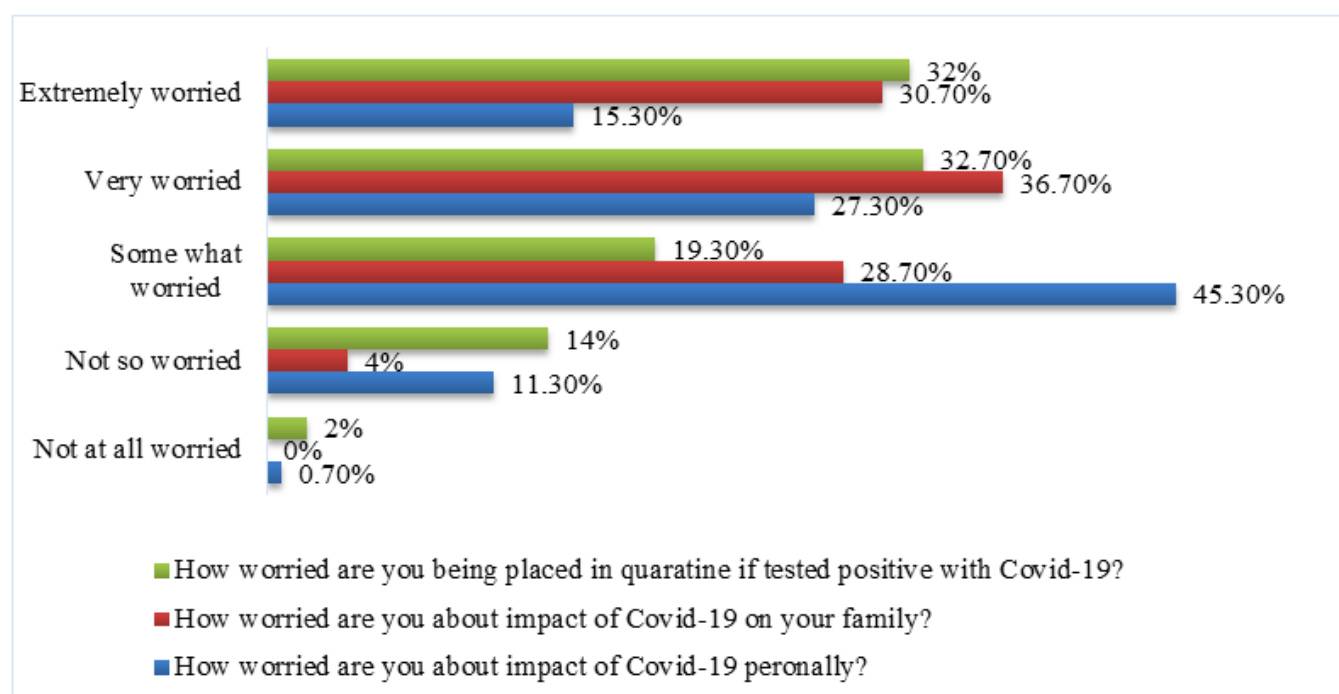

Figure 2: Physicians' concerns about the impact of COVID-19 on them personally, on their families, and if they are quarantined

When primary care physicians were asked about concerns regarding rapidly changing COVID-19 guidelines, $40.7 \%$ of respondents had moderate concerns, and $29.3 \%$ were concerned a lot. The majority of the respondents agreed on the availability of personal protective equipment (80\%), while (36.7\%) strongly agreed and (43.3\%) somewhat agreed.

Stress, anxiety, depression, and burnout before COVID-19 pandemic

Primary care physicians were asked if they experienced stress, anxiety, depression, and professional burnout before the COVID-19 pandemic.
An overwhelming majority (78\%) stated that they had none of these before the COVID-19 pandemic. The percentage of physicians who self-reported stress and professional burnout before the COVID-19 pandemic was $8.7 \%$. (2.7\%) reported that they had anxiety, and $2 \%$ had depression before the COVID-19 pandemic.

\section{Stress, anxiety, depression, burnout, professional fulfilment during COVID-19 pandemic}

Stress was reported by $26.7 \%$ of primary care physicians, with $4 \%$ reporting extremely severe stress, $9.3 \%$ reporting severe stress, $8.7 \%$ reporting moderate stress, and $(4.7 \%)$ reporting mild stress. Anxiety has 
Muhammad Atif Waheed et al; Sch J App Med Sci, Jan, 2022; 10(1): 15-24

been reported by $(32.7 \%)$ of physicians. (4.7\%) expressed severe anxiety, (11.3\%) moderate anxiety, and $(16.7 \%)$ mild anxiety. A total of $45.34 \%$ of physicians who replied to the survey said they were depressed, with $2.7 \%$ reporting severe depression,
$10.0 \%$ reporting moderate-to-severe depression, and $(22.7 \%)$ reporting mild depression. $38.7 \%$ of physicians report burnout, with $80 \%$ reporting a low professional fulfilment. These are summarised in Figure 3.

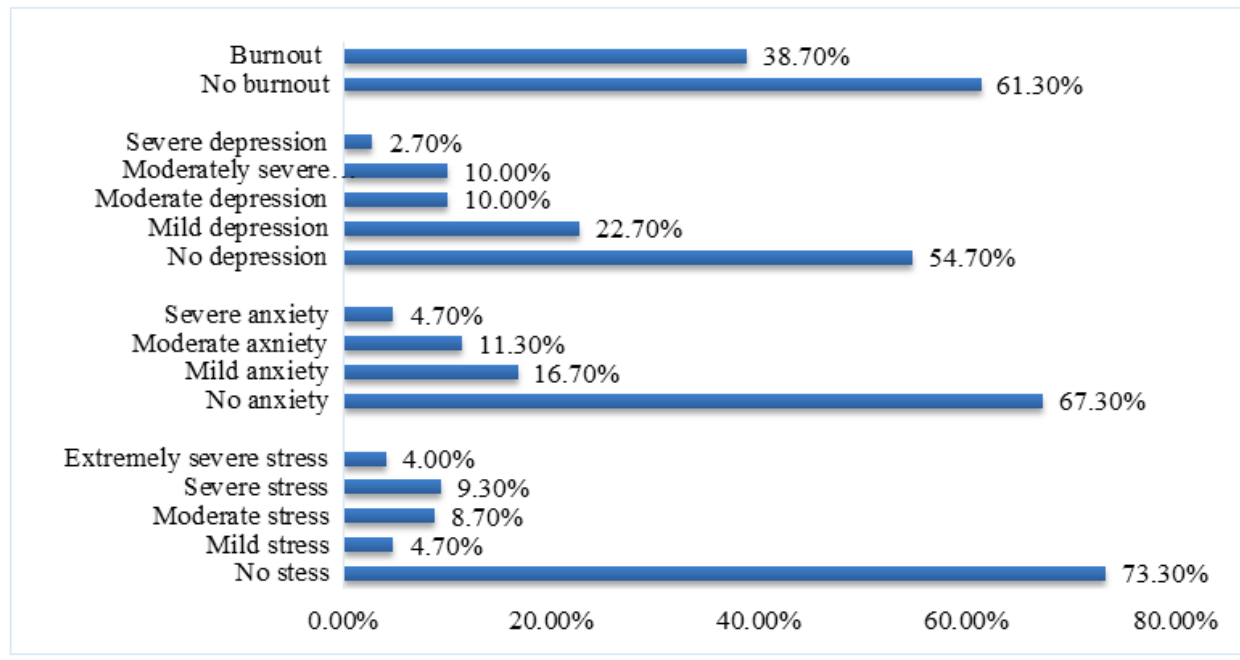

Figure 3: Burnout, depression, anxiety, and stress due to the COVID-19 pandemic

\section{Medical errors}

Since the COVID-19 pandemic, primary care physicians have self-reported the following medical errors: ordering the wrong laboratory test (20\%), ordering the wrong medication (24\%), a medical error that resulted in patient harm $(5.4 \%)$, and a major medical error that could have resulted in patient harm $(9.9 \%)$. The details are summarised in Figure 4.

\footnotetext{
I ordered the wrong lab test

I ordered wrong medication

- I made a medical error that did result in patient harm

- I made a medical error that could have resulted in patient harm
}

Figure 4: Self-reported medical errors

\section{Sociodemographic characteristics and outcomes of psychological distresses}

As demonstrated in Table 2, the prevalence of stress was substantially higher among physicians under 44 years old $(38.0 \%)$ than among physicians $45-54$ years old $(21.1 \%)$ and over 55 years old $(4.5 \%)$. Similarly, we discovered that as participants got older, the prevalence of burnout decreased and professional fulfilment increased. Burnout was found to be $(56.3 \%)$ among physicians under 44 years old, (26.3\%) among physicians 45 to 54 years old, and (13.6\%) among physicians over 55 years old. Professional fulfilment was reported as low by approximately $(88.7 \%)$ of those under the age of 44 , but improved to 73.7 in the $45-54$ age group and further improved in respondents aged 55 and above $(68.2 \% ; p=.035)$. Gender, marital status, and the number of dependents were not associated with stress, anxiety, depression, burnout, and low professional fulfilment $(p>.05)$. 
Table 2: Association of stress, anxiety, depression, burnout, and low professional fulfilment index among primary care physicians with socio-demographics $(\mathbf{N}=150)$.

\begin{tabular}{|c|c|c|c|c|c|}
\hline & Stress & Anxiety & Depression & Burnout & Low (PFI) \\
\hline & $\mathrm{n}(\%)$ & $\mathrm{n}(\%)$ & $\mathrm{n}(\%)$ & $\mathrm{n}(\%)$ & $\mathrm{n}(\%)$ \\
\hline \multicolumn{6}{|l|}{ Age groups } \\
\hline$<44$ & $27(38.0) *$ & $25(35.2)$ & $35(49.3)$ & $40(56.3) * *$ & $63(88.7) * * *$ \\
\hline 45 to 54 & $12(21.1)$ & $16(28.1)$ & $25(43.9)$ & $15(26.3)$ & $42(73.7)$ \\
\hline$>55$ & $1(4.5)$ & $8(36.4)$ & $8(36.4)$ & $3(13.6)$ & $15(68.2)$ \\
\hline \multicolumn{6}{|l|}{ Gender } \\
\hline Female & $20(32.3)$ & $25(40.3)$ & $33(53.2)$ & $26(41.9)$ & $50(80.6)$ \\
\hline Male & $20(22.7)$ & $24(27.3)$ & $35(39.8)$ & $32(36.4)$ & $70(79.5)$ \\
\hline \multicolumn{6}{|l|}{ Marital status } \\
\hline Married & $37(26.2)$ & $47(33.3)$ & $66(46.8)$ & $54(38.3)$ & 114(80.9) \\
\hline Currently Single & $3(33.3)$ & $2(22.2)$ & $2(22.2)$ & $4(44.4)$ & $6(66.7)$ \\
\hline \multicolumn{6}{|l|}{ Dependents } \\
\hline None & $8(38.1)$ & $6(28.6)$ & $9(42.9)$ & 11(52.4) & $18(85.7)$ \\
\hline 1 & $6(35.3)$ & $8(47.1)$ & $7(41.2)$ & $8(47.1)$ & $14(82.4)$ \\
\hline 2 & $11(24.4)$ & $16(35.6)$ & $22(48.9)$ & 13(28.9) & $34(75.6)$ \\
\hline 3 & $10(25.0)$ & $12(30.0)$ & $20(50.0)$ & $16(40.0)$ & $35(87.5)$ \\
\hline 4 & $3(23.1)$ & $4(30.8)$ & $7(53.8)$ & $7(53.8)$ & $11(84.6)$ \\
\hline$>4$ & $2(14.3)$ & $3(21.4)$ & $3(21.4)$ & $3(21.4)$ & $18(85.7)$ \\
\hline \multicolumn{3}{|c|}{$* p=.004, * * p=<.001, * * * p=.035$} & & & \\
\hline
\end{tabular}

Stress, anxiety, depression, low professional fulfilment, and burnout association with individual, familial and quarantine factors

Physicians who were personally concerned about the impact of COVID-19 experienced higher levels of stress $(29.5 \%)$, anxiety $(35.6 \%)$, and depression $(49.2 \%)$ than those who were not $(p<.05)$. Primary care physicians who were worried of being quarantined had a higher rate of depression (49.2\%) than those who were not $(25.0 \%, p<.05)$. Low professional fulfilment was found to be high among physicians who were worried about their families $(81.3 \%)$, compared to those who were not worried $(50 \%)$, but this was not statistically significant ( $p$ $=.061)$. The results are summarised in Table 3 .

Table 3: Association of stress, anxiety, depression, low professional fulfilment, and burnout among primary care physicians with individual, familial and quarantine factors $(\mathrm{N}=150)$

\begin{tabular}{|c|c|c|c|c|c|c|}
\hline & & Stress & Anxiety & Depression & Low (PFI) & Burnout \\
\hline & & $\mathrm{n}(\%)$ & $\mathrm{n}(\%)$ & $\mathrm{n}(\%)$ & $\mathrm{n}(\%)$ & $\mathrm{n}(\%)$ \\
\hline \multirow[t]{2}{*}{ Personal } & Not worried & $1(5.6)$ & $2(11.1)$ & $3(16.7)$ & $14(77.8)$ & $7(38.9)$ \\
\hline & Worried & $39(29.5) *$ & $47(35.6) * *$ & $65(49.2) * * *$ & $106(80.3)$ & $51(38.6)$ \\
\hline \multirow[t]{2}{*}{ Family } & Not worried & $1(16.7)$ & $1(16.7)$ & $1(16.7)$ & $3(50.0)$ & $2(33.3)$ \\
\hline & Worried & $39(27.1)$ & $48(33.3)$ & $67(46.5)$ & $117(81.3)$ & $56(38.9)$ \\
\hline \multirow[t]{2}{*}{ Quarantine } & Not worried & $4(16.7)$ & $4(16.7)$ & $6(25.0) * * * *$ & $18(75.0)$ & $8(33.3)$ \\
\hline & Worried & $36(28.6)$ & $45(35.7)$ & $62(49.2)$ & $102(81.0)$ & $50(39.7)$ \\
\hline
\end{tabular}

Stress, anxiety, depression, burnout, and PFI association with rapidly changing COVID-19 guidelines, salary satisfaction, virtual consultations and the availability of personal protection equipment

No significant relationship was found between stress, anxiety, depression, burnout, and PFI, with rapidly changing COVID-19 guidelines and the availability of personal protection equipment $(p>.05)$. However, virtual consultation dissatisfaction was significantly associated with stress $(p=.006)$, anxiety ( $p$ $=.028)$, depression $(p=.010)$, and burnout $(p=.038)$. Similarly, salary dissatisfaction was significantly associated with stress $(p=.047)$ and depression ( $p$ $=.005)$.
Stress, anxiety, depression, burnout, and PFI association with medical errors

Among the physicians who reported some form of stress, $20.0 \%$ said they made a major medical error that could have resulted in patient harm compared to $6.4 \%$ with no stress $(p=.014)$. Similarly, physicians with anxiety $(p=.003)$ and physicians with depression ( $p=.022$ ) were more likely to report making a major medical error that could have resulted in patient harm. Furthermore, physicians who reported burnout were more likely to order the wrong medication $(p=.046)$, and physicians who reported stress, anxiety, or burnout were more likely to order the wrong laboratory test $(p<.05)$. 
Muhammad Atif Waheed et al; Sch J App Med Sci, Jan, 2022; 10(1): 15-24

Correlation between stress, anxiety, depression, burnout and professional fulfilment

Spearman's rank-order correlation was used to determine the relationship between burnout, professional fulfilment, stress, anxiety, and depression, which are summarised in Table 4. Burnout was found to be moderately positively correlated (Akoglu, 2018) to stress, anxiety, and depression ( $\mathrm{rs}=.611, \mathrm{p}<.001$; $\mathrm{rs}=$ $.539, p<.001 ; \mathrm{rs}=.556, p<.001)$. The professional fulfilment index was moderately negatively correlated with stress, anxiety, depression, and burnout ( $\mathrm{rs}=-.522$, $p<.001)$; $(\mathrm{rs}=-.484, p<.001) ;(\mathrm{rs}=-.498, p<.001)$; ( $\mathrm{rs}=-.564, p<.001)$. Anxiety was strongly positively related to stress, depression, and moderately with burnout ( $\mathrm{rs}=.828, p<.001$; $(\mathrm{rs}=.874, p<.001)$; $(\mathrm{rs}=$ $.539, p<.001)$. Depression was strongly positively related to stress and anxiety and moderately correlated with burnout ( $\mathrm{rs}=.787, p<.001)$; $(\mathrm{rs}=.874, p<.001)$, and $(\mathrm{rs}=.556, p<.001)$.

Table 3: Spearman rho correlation between stress, anxiety, depression, professional fulfilment index, and burnout (N=150)

\begin{tabular}{|l|l|l|l|l|l|l|}
\hline & & Depression & Anxiety & Stress & PFI & Burnout \\
\hline \multirow{5}{*}{ Depression } & Correlation Coefficient & 1 & $.874^{* *}$ & $.787^{* *}$ & $-.498^{* *}$ & $.556^{* *}$ \\
\cline { 2 - 7 } & Sig. (2-tailed) &. & 0.000 & 0.000 & 0.000 & 0.000 \\
\cline { 2 - 7 } & $\mathrm{N}$ & 150 & 150 & 150 & 150 & 150 \\
\hline \multirow{5}{*}{ Anxiety } & Correlation Coefficient & $.874^{* *}$ & 1 & $.828^{* *}$ & $-.484^{* *}$ & $.539^{* *}$ \\
\cline { 2 - 7 } & Sig. (2-tailed) & 0.000 &. & 0.000 & 0.000 & 0.000 \\
\cline { 2 - 7 } & $\mathrm{N}$ & 150 & 150 & 150 & 150 & 150 \\
\hline \multirow{5}{*}{ PFI I } & Correlation Coefficient & $.787^{* *}$ & $.828^{* *}$ & 1 & $-.522^{* *}$ & $.611^{* *}$ \\
\cline { 2 - 7 } & Sig. (2-tailed) & 0.000 & 0.000 &. & 0.000 & 0.000 \\
\cline { 2 - 7 } & $\mathrm{N}$ & 150 & 150 & 150 & 150 & 150 \\
\cline { 2 - 7 } & Correlation Coefficient & $-.498^{* *}$ & $-.484^{* *}$ & $-.522^{* *}$ & 1 & $-.564^{* *}$ \\
\cline { 2 - 7 } & Sig. (2-tailed) & 0.000 & 0.000 & 0.000 &. & 0.000 \\
\cline { 2 - 7 } & $\mathrm{N}$ & 150 & 150 & 150 & 150 & 150 \\
\hline \multirow{5}{*}{ Burnout } & Correlation Coefficient & $.556^{* *}$ & $.539^{* *}$ & $.611^{* *}$ & $-.564^{* *}$ & 1 \\
\cline { 2 - 7 } & Sig. (2-tailed) & 0.000 & 0.000 & 0.000 & 0.000 &. \\
\cline { 2 - 7 } & $\mathrm{N}$ & 150 & 150 & 150 & 150 & 150 \\
\hline
\end{tabular}

\section{DISCUSSION}

This is the first study to emphasise the impact of COVID-19 pandemic on the WLB of primary care physicians within the Middle Eastern region. A considerable number of primary care physicians have stress $(26.7 \%)$, anxiety $(32.7 \%)$, depression $(45.3 \%)$, burnout $(38.7 \%)$ and low professional fulfilment $(80 \%)$. Before the COVID-19 pandemic, primary care physicians self-reported prevalence of stress and burnout were $8.7 \%$, while anxiety and depression as $2.7 \%$ and $2 \%$, respectively. Amin et al., (2020) found the prevalence of anxiety and depression among frontline physicians in Pakistan as $43 \%$ at the beginning of the COVID-19 pandemic. These findings are similar to those found in this study. In a survey conducted by Medscape, approximately $79 \%$ of family physicians were happy outside of work before the COVID-19 pandemic. This rate dropped to $57 \%$ during the pandemic period. However, no significant difference in burnout was found before the COVID-19 pandemic; it was $46 \%$, and during the COVID-19 pandemic, $47 \%$, respectively (Medscape, 2021).

Physicians under 44 years of age are at risk for stress, burnout, and low professional fulfilment, which is consistent with the existing findings in the literature (Huang et al., 2020). Physicians over 55 years of age are twice as less at risk of burnout than those below 55 years old (Poghosyan, 2018). This could be due to the experience factor, as less experience is a risk factor for high burnout (Wang et al., 2014). Moreover, being single and having a female gender are other risk factors for burnout. Hansen et al., (2018) found in a study conducted across United States of America that the prevalence of burnout among family physicians was $25-63 \%$ and it was considerably higher among female physicians below 40 years of age. In another study conducted among practising family physicians applying for the American Board of Family Medicine certification examination, total burnout was $24.5 \%$, and female gender was significantly associated with burnout (Puffer et al., 2017). Physicians with inadequate social support systems (having no spouse, children, or partners) are at a higher risk of burnout (Patel et al., 2018). However, in our study, gender, marital status, and the number of dependents were not associated with stress, anxiety, depression, burnout, and professional fulfilment. This could be due to the better social support system in Qatar.

Physicians worried about COVID-19's impact personally had statistically significant higher levels of stress, anxiety, and depression compared to those who were not worried. Depression was found to be significantly higher in physicians who were worried about being quarantined. Quarantine and isolation lead to adverse mental health outcomes such as anxiety, depression, fear, insomnia, and other psychological 
Muhammad Atif Waheed et al; Sch J App Med Sci, Jan, 2022; 10(1): 15-24

distress (Hossain et al., 2020). Reducing uncertainty is necessary to reduce psychological distress. Fear is exacerbated by uncertainty (Mertens et al., 2020; Hancock and Mattick, 2020). It is worth noting that physicians who were stressed, anxious, or depressed were more likely to make a major medical error that could have resulted in patient harm, and physicians who reported burnout were more likely to order the wrong medication and laboratory tests.

In this study, telephone consultation dissatisfaction was significantly associated with stress, anxiety, depression, and burnout. Telephone consultations for patient triage can add to the stress of primary care (Welch, 2017). Although most family physicians were satisfied with telephone consultations at $65.4 \%$ during this ongoing COVID-19 pandemic, it is lower than the literature findings of $80 \%$ and above for telehealth (Andrews et al., 2020). This could be for cultural and linguistic reasons. Ogundipe et al., (2014) concluded that burnout and salary dissatisfaction are not related. Dissatisfaction with salary was associated with stress and depression, but not with burnout in our study. The lack of personal protective equipment is a risk factor for burnout and other mental health conditions (Sasangohar et al, 2020). Similarly, burnout is higher in physicians who do not choose medicine as a profession voluntarily (Dinibutun et al, 2020). Our findings conclude that the availability of PPE, choosing medicine as a profession willingly or unwillingly, and the rapidly changing COVID-19 guidelines were not significantly associated with stress, anxiety, depression, burnout, and professional fulfilment. It is noticeable that the difference in the effect of rapidly changing COVID-19 guidelines was not seen in our study due to the timely and appropriate dissemination of decisionmaking tools and algorithms provided by the Centre for Disease Control and PHCC higher management.

Primary Healthcare Corporation, Qatar, has been very proactive since the beginning of COVID-19 to support primary care physicians. An extra budget has been allocated for employees working extra hours in COVID-19 related services, limiting the maximum hours worked per week to prevent burnout. The community call centre was established in March 2020 to provide virtual consultations with the placement of high-risk staff. The firm has also provided regular breaks across all health centres and refreshments for physicians working in COVID-19 related services. The availability of personal protective equipment was ensured at all times. Staff have been supported by active hotlines for ethical concerns, mental health support, and occupational health services. Updated COVID-19 related guidelines have been regularly shared with all physicians and staff by the Infection Prevention and Control Department to keep them updated. All these measures have certainly helped primary care physicians attain a better work-life balance, as worrying about the self-impact of COVID-19 has a significant relationship with stress, anxiety, and depression, as found in this study.

\section{Limitations and Future Research}

There are a few limitations to our study. First, this study was conducted at a single institute, and the response rate was low, limiting the study's external validity because small sample size results should be interpreted with caution, particularly confidence intervals and P values (Hackshaw, 2008). However, the results of this study can be generalised to all primary care physicians in Qatar, as PHCC is the primary provider of primary healthcare services to Qatar's residents and citizens through its 28 health centres located throughout the country (PHCC, 2021). Moreover, in a questionnaire survey, the response rate is $10 \%$ or less (Collis and Hussey, 2013), and in the field of health research, survey response rates have generally been declining over the last decade (Cunningham et al, 2015). The physician response rates for surveys have continued to drop (Delnevo and Singh, 2021). Second, we included possible dimensions that could lead to stress, anxiety, depression, burnout, and lower professional fulfilment. However, these were limited because other factors such as exercise, sleep, shift work, stress from treating COVID-19 patients, and social distancing were not assessed.

\section{CONCLUSION}

COVID-19 pandemic has impacted negatively on primary care physicians work life balance in terms of psychological distresses and professional fulfilment. These symptoms may negatively impact their job performance. Physicians younger than forty-four years of age need support mechanism that can help to mitigate psychological distress which has led to medical errors, wrong prescriptions, and incorrect laboratory testing. Perhaps, regular assessment of psychological distresses is advised. Quarantine and isolation fears which leads to mental distress can be reduced via carefully calibrated communication which should avoid fear-based communication, rather should be empathetic and physician centred as fear increases uncertainty and thus psychological distresses. Although Primary Healthcare Corporation, Qatar has taken all significant and excellent steps to support physicians during the COVID-19 pandemic, as highlighted in this paper, the COVID-19 pandemic's adverse effects are immense worldwide and have a continued impact on frontline healthcare staff. Refreshing training in virtual consultation and provision of online interpreter services can help improve primary care physicians' satisfaction and thus reduce stress, anxiety, depression, and burnout.

Competing interest's statement: The authors have declared that no competing interests exist.

Funding: The author(s) received no specific funding for this work. 
Muhammad Atif Waheed et al; Sch J App Med Sci, Jan, 2022; 10(1): 15-24

Ethical approval: The $P H C C$ research subcommittee approved this research. The other ethics committee approval was not applicable.

Ethics Statement: Implied consent was included in the first page of the online questionnaire

\section{REFERENCES}

- Akoglu, H. (2018). User's guide to correlation coefficients. Turkish journal of emergency medicine, 18(3), 91-93.

- Amin, F., Sharif, S., Saeed, R., Durrani, N., \& Jilani, D. (2020). COVID-19 pandemic-knowledge, perception, anxiety and depression among frontline doctors of Pakistan. BMC psychiatry, 20(1), 1-9.

- Andrews, E., Berghofer, K., Long, J., Prescott, A., \& Caboral-Stevens, M. (2020). Satisfaction with the use of telehealth during COVID-19: An integrative review. International journal of nursing studies advances, 2, 100008.

- Casigliani, V., De Nard, F., De Vita, E., Arzilli, G., Grosso, F. M., Quattrone, F., ... \& Lopalco, P. (2020). Too much information, too little evidence: is waste in research fuelling the covid-19 infodemic. bmj, 370, m2672.

- Collis, J., \& Hussey, R. (2013). Business research: A practical guide for undergraduate and postgraduate students. Macmillan International Higher Education.

- Cunningham, C. T., Quan, H., Hemmelgarn, B., Noseworthy, T., Beck, C. A., Dixon, E., ... \& Jetté, N. (2015). Exploring physician specialist response rates to web-based surveys. BMC medical research methodology, 15(1), 1-8.

- Delnevo, C. D., \& Singh, B. (2021). The effect of a web-push survey on physician survey responses rates: a randomized experiment. Survey practice, $14(1)$.

- Dinibutun, S. R. (2020). Factors associated with burnout among physicians: an evaluation during a period of COVID-19 pandemic. Journal of healthcare leadership, 12, 85.

- Hacimusalar, Y., Kahve, A. C., Yasar, A. B., \& Aydin, M. S. (2020). Anxiety and hopelessness levels in COVID-19 pandemic: A comparative study of healthcare professionals and other community sample in Turkey. Journal of psychiatric research, 129, 181-188.

- Hackshaw, A. (2008). Small studies: strengths and limitations. European Respiratory Journal, 32(5), 1141-1143.

- Hancock, J., \& Mattick, K. (2020). Tolerance of ambiguity and psychological well-being in medical training: a systematic review. Medical education, 54(2), 125-137.

- Hansen, A., Peterson, L. E., Fang, B., \& Phillips, R. L. (2018). Burnout in young family physicians: variation across states. The Journal of the American Board of Family Medicine, 31(1), 7-8.

- He, X. Y. L. C., Li, C., Qian, J., Cui, H. S., \& Wu, W. (2010). Reliability and validity of a generalized anxiety disorder scale in general hospital outpatients. Shanghai Arch Psychiatry, 22(4), 200203.

- Hirschi, A., Shockley, K. M., \& Zacher, H. (2019). Achieving work-family balance: An action regulation model. Academy of Management Review, 44(1), 150-171.

- Hossain, M. M., Sultana, A., \& Purohit, N. (2020). Mental health outcomes of quarantine and isolation for infection prevention: a systematic umbrella review of the global evidence. Epidemiology and health, 42 .

- Huang, L., Caspari, J. H., Sun, X., Thai, J., Li, Y., Chen, F. Z., \& Zhao, X. D. (2020). Risk and protective factors for burnout among physicians from standardized residency training programs in Shanghai: a cross-sectional study. BMC Health Services Research, 20(1), 1-12.

- Kannampallil, T. G., Goss, C. W., Evanoff, B. A., Strickland, J. R., McAlister, R. P., \& Duncan, J. (2020). Exposure to COVID-19 patients increases physician trainee stress and burnout. PloS one, 15(8), e0237301.

- $\quad$ Lai, J., Ma, S., Wang, Y., Cai, Z., Hu, J., Wei, N., ... \& Hu, S. (2020). Factors associated with mental health outcomes among health care workers exposed to coronavirus disease 2019. JAMA network open, 3(3), e203976-e203976.

- Lindfelt, T., Ip, E. J., Gomez, A., \& Barnett, M. J. (2018). The impact of work-life balance on intention to stay in academia: results from a national survey of pharmacy faculty. Research in Social and Administrative Pharmacy, 14(4), 387390.

- Lockwood, N. R. (2003). Work/life balance. Challenges and Solutions, SHRM Research, USA, 2-10.

- Medscape, (2021). Retrieved 20 April 2021, from https://www.medscape.com/slideshow/2021lifestyle-family-medicine-6013509

- Mertens, G., Gerritsen, L., Duijndam, S., Salemink, E., \& Engelhard, I. M. (2020). Fear of the coronavirus (COVID-19): Predictors in an online study conducted in March 2020. Journal of anxiety disorders, 74, 102258.

- O’Brien, J. M., Goncin, U., Ngo, R., Hedlin, P., \& Chakravarti, A. (2021). Professional fulfillment, burnout, and wellness of anesthesiologists during the COVID-19 pandemic. Canadian Journal of Anesthesia/Journal canadien d'anesthésie, 68(5), 734-736.

- Ogundipe, O. A., Olagunju, A. T., Lasebikan, V. O., \& Coker, A. O. (2014). Burnout among doctors in residency training in a tertiary hospital. Asian journal of psychiatry, 10, 27-32. 
- $\quad$ Patel, R. S., Bachu, R., Adikey, A., Malik, M., \& Shah, M. (2018). Factors related to physician burnout and its consequences: a review. Behavioral sciences, 8(11), 98.

- $\quad$ PHCC. (2021). Health Centers. Retrieved 20 April, 2021, from https://www.phcc.gov.qa/en/HealthCenters/All-Health-Centers

- Poghosyan, L. (2018). Clinican Burnout: New Times, Old Issue. Nursing Economics, 36(3), 109111.

- Puffer, J. C., Knight, H. C., O'Neill, T. R., Rassolian, M., Bazemore, A. W., Peterson, L. E., \& Baxley, E. G. (2017). Prevalence of burnout in board certified family physicians. The Journal of the American Board of Family Medicine, 30(2), $125-126$

- $\quad$ Sasangohar, F., Jones, S. L., Masud, F. N., Vahidy, F. S., \& Kash, B. A. (2020). Provider burnout and fatigue during the COVID-19 pandemic: lessons learned from a high-volume intensive care unit. Anesthesia and analgesia.

- Sinclair, S. J., Siefert, C. J., Slavin-Mulford, J. M., Stein, M. B., Renna, M., \& Blais, M. A. (2012). Psychometric evaluation and normative data for the depression, anxiety, and stress scales-21 (DASS21) in a nonclinical sample of US adults. Evaluation \& the health professions, 35(3), 259-279.

- Tavakol, M., \& Dennick, R. (2011). Making sense of Cronbach's alpha. International journal of medical education, 2, 53.
- Trockel, M., Bohman, B., Lesure, E., Hamidi, M. S., Welle, D., Roberts, L., \& Shanafelt, T. (2018). A brief instrument to assess both burnout and professional fulfillment in physicians: reliability and validity, including correlation with selfreported medical errors, in a sample of resident and practicing physicians. Academic Psychiatry, 42(1), 11-24.

- Wang, Z., Xie, Z., Dai, J., Zhang, L., Huang, Y., \& Chen, B. (2014). Physician burnout and its associated factors: a cross-sectional study in Shanghai. Journal of occupational health, 13-0108.

- Welch, C. J. (2017). Telephone triage could further stress primary care. Bmj, 359.

- West, C. P., Dyrbye, L. N., \& Shanafelt, T. D. (2018). Physician burnout: contributors, consequences and solutions. Journal of internal medicine, 283(6), 516-529.

- WHO Coronavirus (COVID-19) Dashboard. (2021). Retrieved 21 April 2021, from https://covid19.who.int/.

- $\quad$ Zhang, Y. L., Liang, W., Chen, Z. M., Zhang, H. M., Zhang, J. H., Weng, X. Q., ... \& Zhang, Y. L. (2013). Validity and reliability of Patient Health Questionnaire-9 and Patient Health Questionnaire2 to screen for depression among college students in China. Asia-Pacific Psychiatry, 5(4), 268-275. 